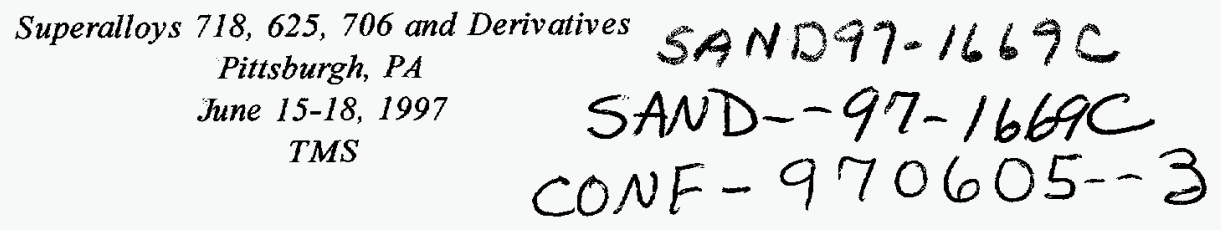

\title{
SOLIDIFICATION MODELING OF Nb BEARING SUPERALLOYS
}

\author{
J.N. DuPont ${ }^{1}$, C.V. Robino ${ }^{2}$, and A.R. Marder ${ }^{1}$ \\ 1. Lehigh University, Bethlehem, PA \\ 2. Sandia National Laboratory, Albuquerque, NM
}

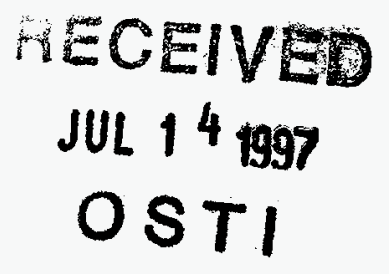

\begin{abstract}
The solidification behavior of experimental $\mathrm{Ni}$ base and $\mathrm{Fe}$ base superalloys containing $\mathrm{Nb}, \mathrm{Si}$, and $\mathrm{C}$ was studied using differential thermal analysis (DTA) and microstructural characterization techniques. The solidification reaction sequences responsible for microstructural development were found to be similar to those expected in the Ni-Nb-C ternary system, where the solute-rich interdendritic liquid exhibited two eutectic-type reactions at the terminal stages of solidification: $\mathrm{L} \rightarrow(\gamma+\mathrm{NbC})$ and $\mathrm{L} \rightarrow$ $(\gamma+$ Laves $)$. A pseudo ternary $\gamma-\mathrm{Nb}-\mathrm{C}$ approach was developed to provide a quantitative description of solidification behavior for these experimental alloys. Solute redistribution calculations in the model are based on a previous approach developed by Mehrabian and Flemings, with modifications made to account for the high diffusion rate of $\mathrm{C}$ in the solid. Solidification parameters for $\mathrm{Nb}$ and $\mathrm{C}$ were determined through DTA and electron probe microanalysis techniques and used as inputs to the model. Reasonable agreement is found between calculated volume fractions of the $\gamma / \mathrm{NbC}$ and $\gamma /$ Laves constituents and those measured experimentally. The modelling results permit detailed descriptions of the relation between alloy composition and microstructural evolution during solidification.
\end{abstract}

\section{INTRODUCTION}

$\mathrm{Ni}$ base and $\mathrm{Fe}$ base $\mathrm{Nb}$-strengthened alloys represent a significant portion of superalloys currently in use. Commercial examples include alloys IN625, IN706, IN718, IN903, IN909, and Thermo-Span, to name a few. These alloys are often used for components which are fabricated by solidification processes such as casting and fusion welding. Previous studies conducted on commercial superalloys $[1,2,3]$ have shown that minor additions of $\mathrm{Nb}, \mathrm{Si}$, and $\mathrm{C}$ strongly affect the type and amount of secondary phases which form during the terminal stages of solidification. In particular, two types of secondary phases, $\mathrm{NbC}$ and Laves, are known to form. Although several detailed investigations have been conducted on specific commercial alloy systems, no general model has been developed to quantitatively predict mic rostructural evolution during solidification. Thus, a solidification model was developed and verified on a wide range of experimental $\mathrm{Fe}$ base and $\mathrm{Ni}$ base alloys containing systematic variations in $\mathrm{Nb}, \mathrm{Si}$, and $\mathrm{C}$. This article will focus on the effects of the two most important solute elements: $\mathrm{Nb}$ and $\mathrm{C}$. More details, which describe the effects of $\mathrm{Si}$ and results of solidification cracking studies, can be found elsewhere [4]. 


\section{DISCLAMMIER}

Portions of this document may be illegible in electronic image products. Images are produced from the best available original docment. 


\section{DISCLAIMER}

This report was prepared as an account of work sponsored by an agency of the United States Government. Neither the United States Government nor any agency thereof, nor any of their employees, make any warranty, express or implied, or assumes any legal liability or responsibility for the accuracy, completeness, or usefulness of any information, apparatus, product, or process disclosed, or represents that its use would not infringe privately owned rights. Reference herein to any specific commercial product, process, or service by trade name, trademark, manufacturer, or otherwise does not necessarily constitute or imply its endorsement, recommendation, or favoring by the United States Government or any agency thereof. The views and opinions of authors expressed herein do not necessarily state or reflect those of the United States Government or any agency thereof. 


\section{EXPERIMENTAL PROCEDURE}

The experimental alloys (Table 1) exhibit factorial variations in $\mathrm{Fe}, \mathrm{Nb}, \mathrm{Si}$, and $\mathrm{C}$ at two levels. The alloys were prepared at Sandia National Laboratory by investment casting. Differential thermal analysis (DTA) was conducted on a Netzsch STA 409 differential thermal analyzer using 500 to $550 \mathrm{mg}$ samples. The DTA system was calibrated to melt within $2{ }^{\circ} \mathrm{C}$ of the melting point of pure $\mathrm{Ni}\left(1455^{\circ} \mathrm{C}\right)$. Samples were melted and solidified under flowing argon in alumina crucibles using pure $\mathrm{Ni}$ as the reference material. Scanning Electron Microscopy was conducted on autogenous GTA weld metals using a JEOL 6300 Field Emission Gun Scanning Electron Microscope (FEG-SEM) at an accelerating voltage of $15 \mathrm{kV}$. Quantitative Image Analy sis (QIA) was performed on GTA welds and selected DTA samples. Area fractions of total eutectic type contents and, where possible, individual $\gamma / \mathrm{NbC}$ and $\gamma /$ Laves eutectic type constituents were measured on each sample with at least ten SEM photomicrographs. Area fractions were assumed to be equivalent to volume fractions. Electron Probe Micro-Analysis (EPMAWDS) was conducted on a JEOL 733 Probe at an accelerating voltage of $15 \mathrm{kV}$ and beam current of $20 \mathrm{nA}$. The $\mathrm{K}_{\alpha}$ lines were used for $\mathrm{Fe}, \mathrm{Ni}, \mathrm{Cr}$, and $\mathrm{Si}$ while the $\mathrm{L}_{\alpha}$ line was used for $\mathrm{Nb}$. Raw data were reduced to weight percentages using the ZAF algorithm.

Table 1. Alloy compositions. All values in weight percent.

\begin{tabular}{||l|l|l|l|l|l|l|l|l||}
\hline Alloy & $\mathrm{Fe}$ & $\mathrm{Ni}$ & $\mathrm{Cr}$ & $\mathrm{Nb}$ & $\mathrm{Si}$ & $\mathrm{C}$ & $\mathrm{P}$ & $\mathrm{S}$ \\
\hline 1 & 10.49 & 68.53 & 18.90 & 1.93 & 0.08 & 0.017 & 0.004 & 0.003 \\
\hline 1.5 & 10.75 & 67.95 & 19.21 & 2.00 & 0.03 & 0.052 & 0.004 & 0.003 \\
\hline 2 & 11.12 & 68.20 & 19.12 & 1.95 & 0.06 & 0.132 & 0.004 & 0.002 \\
\hline 3 & 10.70 & 68.11 & 19.02 & 1.82 & 0.38 & 0.010 & 0.004 & 0.003 \\
\hline 3.5 & 10.39 & 66.80 & 19.29 & 1.94 & 0.41 & 0.075 & 0.004 & 0.003 \\
\hline 4 & 10.72 & 67.60 & 19.08 & 1.91 & 0.40 & 0.155 & 0.004 & 0.001 \\
\hline 5 & 10.84 & 65.79 & 18.98 & 5.17 & 0.05 & 0.013 & 0.005 & 0.010 \\
\hline 6 & 10.88 & 65.22 & 18.89 & 4.87 & 0.08 & 0.161 & 0.005 & 0.007 \\
\hline 7 & 10.70 & 65.53 & 19.30 & 4.86 & 0.52 & 0.010 & 0.005 & 0.009 \\
\hline 7.5 & 10.82 & 63.93 & 18.54 & 4.92 & 0.46 & 0.081 & 0.005 & 0.004 \\
\hline 8 & 10.80 & 64.96 & 18.90 & 4.72 & 0.52 & 0.170 & 0.005 & 0.007 \\
\hline \hline 9 & 46.03 & 33.56 & 19.31 & 1.66 & 0.10 & 0.003 & 0.006 & 0.003 \\
\hline 10 & 46.69 & 32.80 & 19.70 & 1.66 & 0.01 & 0.108 & 0.006 & 0.002 \\
\hline 11 & 45.38 & 32.80 & 19.53 & 1.77 & 0.57 & 0.004 & 0.006 & 0.002 \\
\hline 11.5 & 47.38 & 31.05 & 19.64 & 1.84 & 0.67 & 0.116 & 0.006 & 0.001 \\
\hline 12 & 45.28 & 32.39 & 19.89 & 1.93 & 0.61 & 0.079 & 0.006 & 0.002 \\
\hline 13 & 44.55 & 31.24 & 19.63 & 4.42 & 0.02 & 0.015 & 0.007 & 0.003 \\
\hline 14 & 44.05 & 31.93 & 19.52 & 4.51 & 0.08 & 0.210 & 0.006 & 0.002 \\
\hline 15 & 45.40 & 30.03 & 19.54 & 4.88 & 0.66 & 0.010 & 0.007 & 0.003 \\
\hline 16 & 44.47 & 30.89 & 19.45 & 4.77 & 0.64 & 0.216 & 0.006 & 0.002 \\
\hline \hline
\end{tabular}




\section{RESULTS AND DISCUSSION}

\section{Solidification Sequences}

The general solidification sequence of these alloys can be described by a three step process: 1) Primary $\mathrm{L} \rightarrow \gamma$ solidification in which the interdendritic liquid becomes enriched in $\mathrm{Nb}$ and $\mathrm{C}$, followed by 2 ) a eutectic-type $L \rightarrow(\gamma+\mathrm{NbC})$ reaction which depletes the interdendritic liquid of $C$, and 3) termination of solidification by a second eutectic-type reaction $\mathrm{L} \rightarrow(\gamma+$ Laves). A typical DTA trace (for Alloy 16) showing this solidification sequence is presented in Figure 1. The microstructure of a GTA weld in Alloy 16 is shown in Figure 2, where the $\gamma / \mathrm{NbC}$ and $\gamma /$ Laves eutectic-type constituents are readily apparent. Identification of the $\mathrm{NbC}$ and Laves phases was confirmed through EPMA measurements on coarse phases in DTA samples and backscattered electron kikuchi patterns collected from finer phases in weld metal samples [4]. The $\mathrm{Ni}$ base alloys with high $\mathrm{C} /$ low $\mathrm{Nb}$ (Alloys 2, 3.5, and 4) represent the only exception to this general solidification sequence. These alloys did not exhibit any of the Laves phase, indicating solidification terminated with the $\mathrm{L} \rightarrow(\gamma+\mathrm{NbC})$ reaction. The individual amounts of the $\gamma / \mathrm{NbC}$ and $\gamma /$ Laves constituents were high enough to quantify by QIA in a number of alloys, and these results are shown in Figure 3. The results from $\mathrm{Ni}$ base and $\mathrm{Fe}$ base alloys are aligned to permit comparisons among alloys with similar solute levels. Carbon additions promote formation of the $\gamma / \mathrm{NbC}$ constituent while $\mathrm{Fe}$ and $\mathrm{Si}$ increase the amount of the $\gamma /$ Laves constituent. The effect of $\mathrm{Nb}$ depends on the $\mathrm{C}$ content. At high $\mathrm{C}$ levels, $\mathrm{Nb}$ additions will promote formation of $\gamma / \mathrm{NbC}$. When the $\mathrm{C}$ level is low, $\mathrm{Nb}$ generally promotes formation of the $\gamma /$ Laves constituent. These effects have been documented in commercial alloy systems as well $[1,2]$.

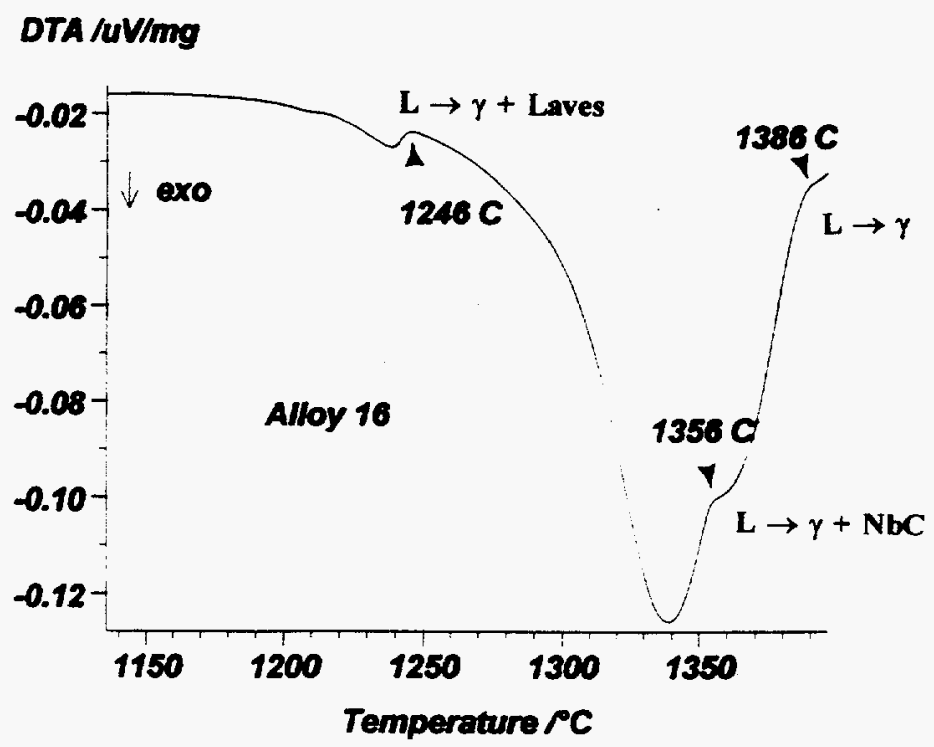

Figure 1. DTA solidification scan for Alloy 16.

The solidification reactions in these experimental multi-component alloys are similar to those expected in the pure ternary $\mathrm{Ni}-\mathrm{Nb}-\mathrm{C}$ system $[5,6]$. The liquidus projection for this system is shown in Figure 4. The liquidus projection exhibits three primary phase fields which are of interest here: $\gamma, \mathrm{NbC}$, and $\mathrm{Ni}_{3} \mathrm{Nb}$. A primary $\mathrm{C}$ (graphite) phase field exists at high $\mathrm{C}$ contents which is not of importance. Additions of $\mathrm{Fe}, \mathrm{Cr}$, and $\mathrm{Si}$ to the $\mathrm{Ni}-\mathrm{Nb}$ system are well known to promote Laves at the expense of $\mathrm{Ni}_{3} \mathrm{Nb}$ in commercial superalloys as well as the experimental alloys utilized in this work $[7,8]$. Thus, by replacing $\mathrm{Ni}_{3} \mathrm{Nb}$ with Laves, the $\mathrm{Ni}-\mathrm{Nb}-\mathrm{C}$ liquidus projection can be utilized as a guide in developing a description of the solidification reactions in these alloys.

Solidification begins with formation of primary $\gamma$ dendrites which, upon forming, reject $\mathrm{Nb}$ and $\mathrm{C}$ to the liquid. As solidification proceeds, the liquid composition moves away from the Ni corner, becoming progressively richer in $\mathrm{Nb}$ and $\mathrm{C}$ until the line of two fold saturation between $\gamma$ and $\mathrm{NbC}$ is reached. At this point, the maximum solubility of $\mathrm{Nb}$ and $\mathrm{C}$ in the austenite matrix is exceeded and the $\gamma$ and $\mathrm{NbC}$ phases form simultaneously from the liquid by a eutectic-type reaction as the liquid 


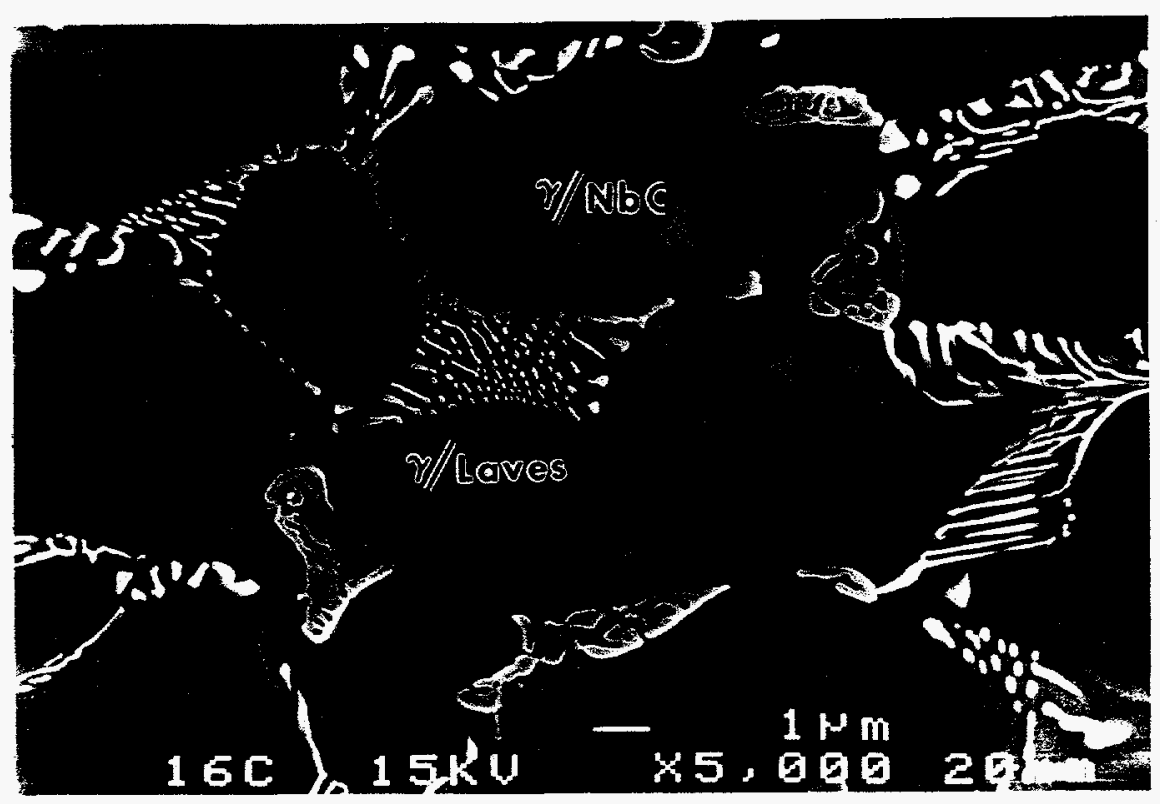

Figure 2. SEM photomicrograph of $\gamma / \mathrm{NbC}$ and $\gamma /$ Laves constituents in GTA weld of Alloy 16.

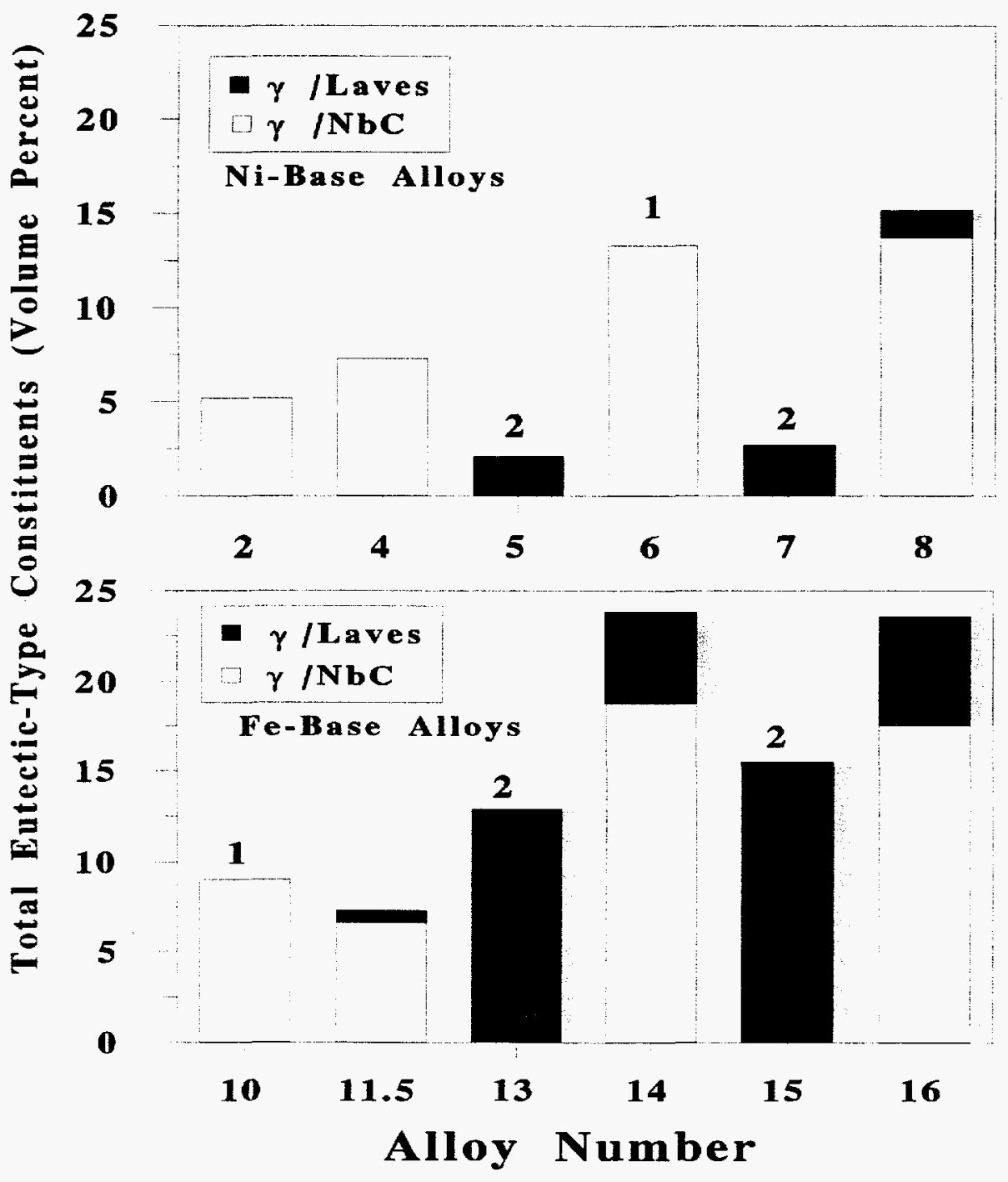

1. Contains trace amounts of $\gamma /$ Laves

2. Contains trace amounts of $\gamma / \mathrm{NbC}$

Figure 3. Quantitaive image analysis results. 
composition travels down the line of two fold saturation. Due to its' high C content ( $9.5 w t \%$, [9]), the formation of $\mathrm{NbC}$ depletes the liquid of $\mathrm{C}$ while the $\mathrm{Nb}$ content of the liquid continues to increase. For Alloys 2, 3.5, and 4, solidification is completed along the line of two fold saturation between $\gamma$ and $\mathrm{NbC}$, as no Laves phase was observed in these alloys. The initial reaction sequence is similar for the remaining alloys, except that solidification does not terminate with the $\mathrm{L} \rightarrow(\gamma+\mathrm{NbC})$ reaction. Instead, the liquid composition continues to travel down the line of two fold saturation between $\gamma$ and $\mathrm{NbC}$, becoming progressively enriched in $\mathrm{Nb}$ (and depleted in $\mathrm{C}$ ). According to the proposed $\mathrm{Ni}-\mathrm{Nb}-\mathrm{C}$ liquidus projection, solidification should terminate with the ternary $\mathrm{L} \rightarrow(\gamma+\mathrm{NbC}+\mathrm{Laves})$ reaction where the liquidus surface is at a minimum. Under this condition, the Laves and ternary $\gamma$ and $\mathrm{NbC}$ phases should be intermixed. However, this type of structure is not observed in any of the alloys which form both the $\mathrm{NbC}$ and Laves phases (e.g., Figure 2). Instead. the $\gamma / \mathrm{NbC}$ and $\gamma /$ Laves eutectic-type constituents are always distinctly separated. This suggests that the pseudo-ternary liquidus projection for the alloys in this work is more properly represented by a class II reaction [10]. In this case, the local minimum on the liquidus surface occurs where the line of two fold saturation separating the $\gamma$ and Laves phases intersects the Ni-Nb "binary" side of the diagram. The liquidus surface in Figure 4 has been drawn to reflect this proposed change. The solidification sequence for alloys with this type of surface would occur as follows. After primary $\gamma$ solidification, the liquid composition travels along the line of two fold saturation separating the $\gamma$ and $\mathrm{NbC}$ phases during the $\mathrm{L} \rightarrow(\gamma+\mathrm{NbC})$ reaction. This process continues until the class II reaction is reached, at which point the $\mathrm{NbC}$ stops forming as the $\mathrm{L}$ $\rightarrow(\gamma+\mathrm{NbC})$ reaction is replaced by the $\mathrm{L} \rightarrow(\gamma+$ Laves $)$ reaction. Solidification is completed at the $\mathrm{Ni}-\mathrm{Nb}$ "binary" side of the diagram by the $\mathrm{L} \rightarrow(\gamma+$ Laves $)$ reaction. This solidification sequence accounts for the two spatially separate $\gamma / \mathrm{NbC}$ and $\gamma /$ Laves eutectic-type constituents which are observed experimentally.

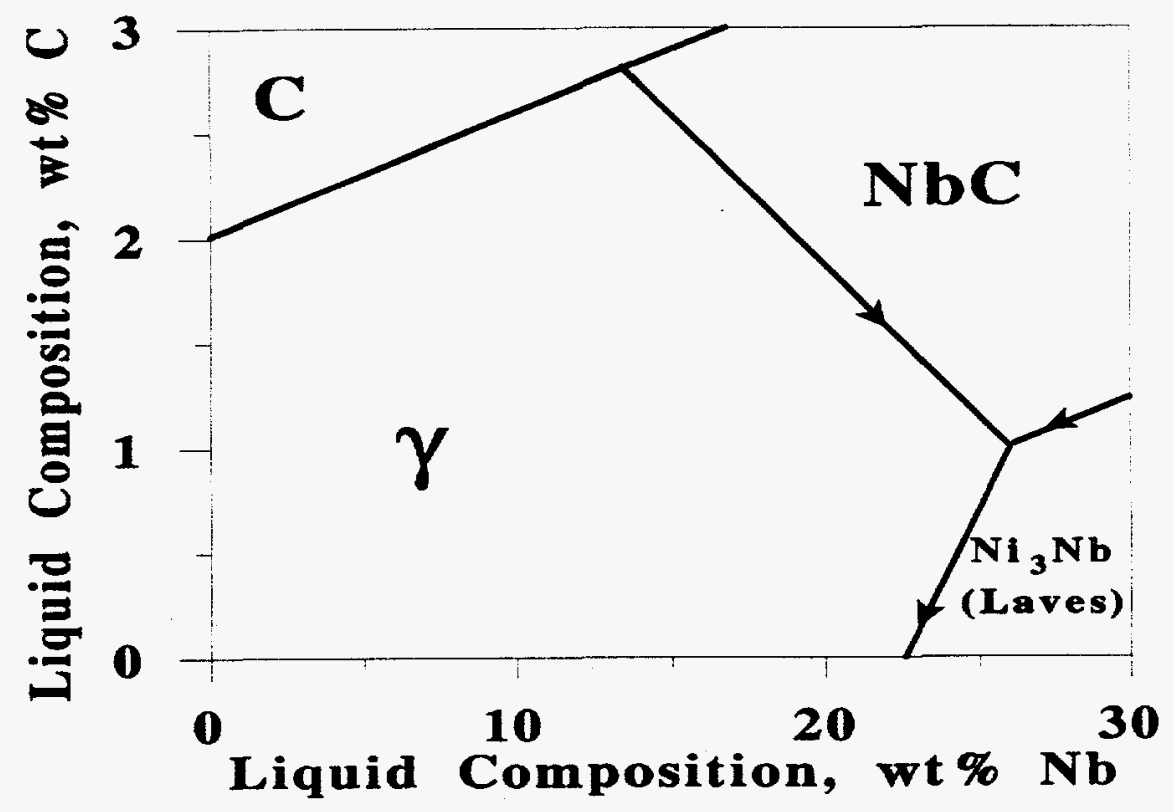

Figure 4. Ni-rich comer of the Ni-Nb-C liquidus projection.

\section{Pseudo-Ternary Solidification Model}

The $\mathrm{Ni}-\mathrm{Nb}-\mathrm{C}$ ternary system forms the basis for developing a model for quantitative prediction of mic rostructural evolution during solidification of these multi-component alloys. The main objective of such a model is to predict the composition and relative fractions of each solid phase forming during the solidification process. Several key elements are required to construct the solidification model. These include the equilibrium distribution coefficients, $\mathrm{k}$, for the solutes $\mathrm{Nb}$ and $\mathrm{C}$, a liquidus surface to identify the lines of two fold saturation separating primary phase fields, and an appropriate solute redistribution model which describes solutal transport in the liquid and solid during solidification. The measurement of $\mathrm{k}$ values and liquidus surfaces for these alloys are described briefly below (more detail can be found in [4]) followed by a description of the solute redistribution model. 
Equilibrium Distribution Coefficients. The equilibrium distribution coefficients are summarized in Table 2. These values were determined by a combination of EPMA and DTA techniques [4]. The $k$ values for $\mathrm{Nb}$ and $\mathrm{C}$ are less than unity, indicating they segregate preferentially to the liquid during solidification. In contrast, the $\mathrm{k}$ values for the "solvent" elements $(\mathrm{Fe} . \mathrm{Ni}, \mathrm{Cr})$ are all close to unity, indicating they show little preference for segregation to either the solid or liquid. It is interesting to note that the value of $k_{N b}$ is significantly lower in the Fe base alloys $\left(k_{N b}=0.25\right)$ compared to the Ni base alloys $\left(\mathrm{k}_{\mathrm{Nb}}=0.46\right)$. Reference to the $\mathrm{Ni}-\mathrm{Nb}$ phase diagram [11] indicates that the maximum solid solubility of $\mathrm{Nb}$ in $\gamma-\mathrm{Ni}$ is $18.2 \mathrm{wt} \% \mathrm{Nb}$ (at $1286^{\circ} \mathrm{C}$ ). In contrast, $\gamma-\mathrm{Fe}$ can only dissolve a maximum of $1.5 \mathrm{wt} \% \mathrm{Nb}$ at a comparable temperature of $1210^{\circ} \mathrm{C}[11]$. Based on these differences, it might be expected that iron additions to these alloys would decrease the solubility of $\mathrm{Nb}$ in the $\gamma-(\mathrm{Fe}, \mathrm{Ni}-\mathrm{Cr})$ matrix. Thus, as the Fe-rich $\gamma$ dendrites begin to form, less $\mathrm{Nb}$ is taken into the solid and, as a result, more is rejected to the liquid (in comparison to the $\mathrm{Ni}$ base alloys). This effect would induce a concomitant decreases in the value of $\mathrm{k}_{\mathrm{Nb}}$. In fact, a general correlation between $\mathrm{k}_{\mathrm{Nb}}$ and nominal iron content has recently been observed [4] over a wide range of matrix compositions.

Pseudo-Temary Solidification Surfaces. Since the alloys in this research contain six elements ( $\mathrm{Fe}, \mathrm{Ni}, \mathrm{Cr}, \mathrm{Nb}, \mathrm{Si}, \mathrm{C}$ ), the term "ternary liquidus projection" can not be properly applied. In addition, the experimental data utilized to construct such projections were derived from welds prepared under nonequilibrium conditions [4]. Thus, the term "pseudo-ternary solidification surface" more appropriately describes these diagrams. The distribution coefficients for the matrix elements $(\mathrm{Fe}, \mathrm{Ni}, \mathrm{Cr}$ ) in commercial systems $[1,3]$ and these experimental alloys are similar and take on a value close to unity, indicating they all behave in a comparable manner and exhibit little tendency for segregation. Thus, the ( $\mathrm{Fe}, \mathrm{Ni}, \mathrm{Cr}$ ) elements in the $\gamma$ matrix are all grouped together to form one "component" of the diagram. Based on the similarity between reaction sequences observed in these multi-component alloys and those expected in the $\mathrm{Ni}-\mathrm{Nb}-\mathrm{C}$ system, $\mathrm{Nb}$ and $\mathrm{C}$ are chosen as the solute elements in this pseudo-ternary solidification model. (Effects from Si are ignored here, but are described in more detail in reference [4].) Lastly, the $\mathrm{Ni}_{3} \mathrm{Nb}$ phase is replaced by the Laves phase. The system can now be represented by a $\gamma-\mathrm{Nb}-\mathrm{C}$ solidification diagram which exhibits primary phase fields of $\gamma, \mathrm{NbC}$, and Laves. The experimentally determined boundaries separating the $\gamma / \mathrm{NbC}$ and $\gamma /$ Laves phase fields are shown in Figure 5. The position of these boundaries was determined with a combination of QIA and EPMA techniques. (The position of the $\mathrm{NbC/Laves} \mathrm{boundary} \mathrm{was} \mathrm{not} \mathrm{determined} \mathrm{as} \mathrm{it} \mathrm{is} \mathrm{not} \mathrm{needed} \mathrm{for} \mathrm{the} \mathrm{present} \mathrm{analy} \mathrm{sis.} \mathrm{The}$ line drawn is provided only for clarity.)

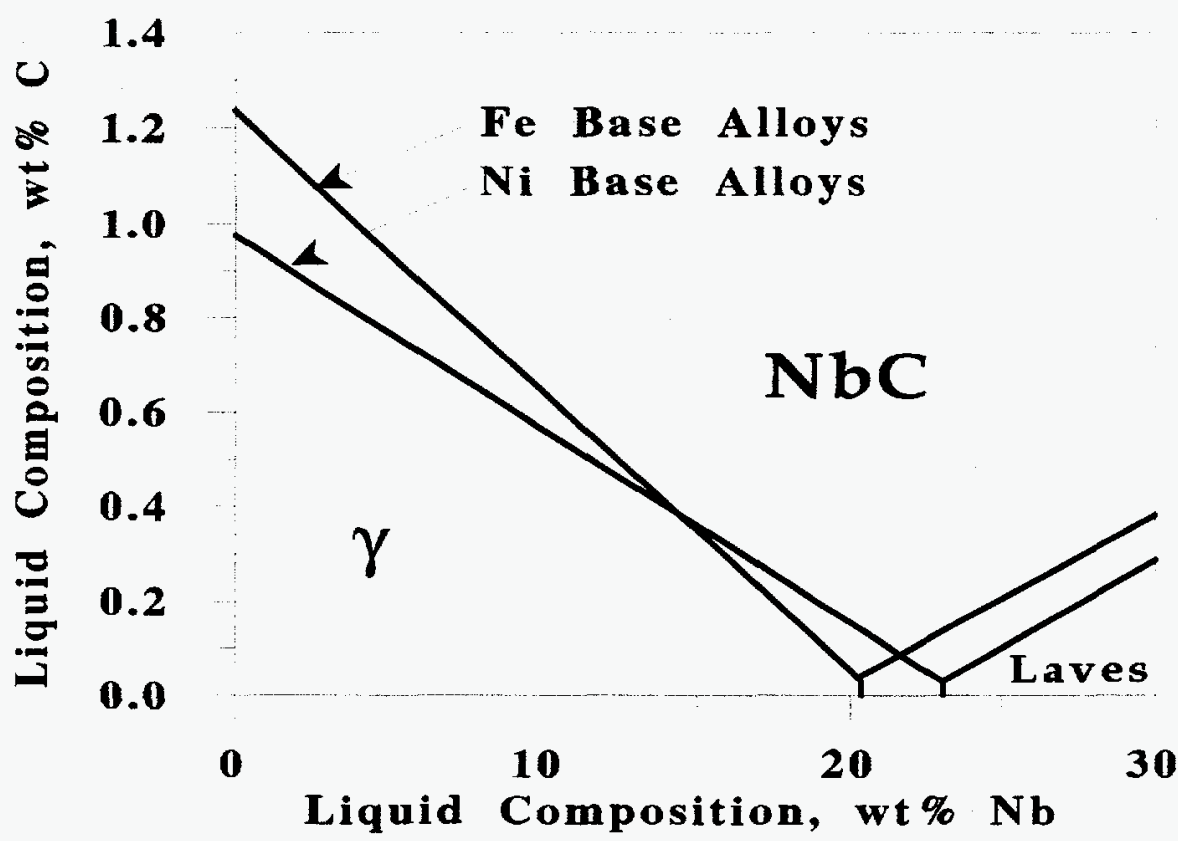

Figure 5. Pseudo-temary $\gamma-\mathrm{Nb}-\mathrm{C}$ solidification surfaces for $\mathrm{Ni}$ base and Fe base alloys. 
Table 2. Distribution coefficients.

\begin{tabular}{|l|l|l|l|l|l|}
\hline Alloys & $\mathrm{Fe}$ & $\mathrm{Ni}$ & $\mathrm{Cr}$ & $\mathrm{Nb}$ & $\mathrm{C}$ \\
\hline Ni-Base & 1.00 & 1.02 & 1.06 & 0.46 & 0.27 \\
\hline Fe-Base & 1.06 & 1.00 & 1.02 & 0.25 & $0.27^{*}$ \\
\hline
\end{tabular}

*Estimated from the $\mathrm{Ni}$ base alloy data

Solute Redistribution Model Quantitative treatment of solute redistribution during solidification of these alloys requires two sets of expressions: one to describe the solidification path (i.e., variation in liquid composition) during primary $\mathrm{L} \rightarrow \gamma$ solidification and one to describe the variation in fraction liquid, $\mathrm{f}_{1}$, with liquid composition, $C_{1}$, during the $\mathrm{L} \rightarrow(\gamma+\mathrm{NbC})$ eutectic-type reaction. The model developed below is based on a previous treatment proposed by Mehrabian and Flemings [12], with modifications being made to account for the high diffusion rate of carbon in the solid. More details of the model are provided in [4].

The solidification path during primary $\mathrm{L} \rightarrow \gamma$ solidification is obtained by first writing the expressions describing the relation between $f_{1}$ and $C_{1}$ for each solute ( $N b$ and $\mathrm{C}$ ). For $\mathrm{Nb}$, diffusion in the solid is negligible $[3,4]$ and the relation between $f_{1}$ and $C_{L, N b}$ is given by the well-known Scheil equation [13].

$$
f_{1}=\left(\frac{C_{1, N b}}{C_{0, N b}}\right)^{\frac{1}{k_{1 b b}-1}}
$$

Eq. (1) also assumes that dendrite tip undercooling is negligible, thermodynamic equilibrium is maintained at the solid/liquid interface, and diffusion is infinitely fast in the liquid. For transport of C, diffusion in the solid is typically fast enough to maintain equilibrium $[4,14]$, and the equilibrium lever law provides the relation between $\mathrm{f}_{1}$ and $\mathrm{C}_{\mathrm{l}, \mathrm{C}}$

$$
f_{1}=\frac{C_{0, c}-k_{c} C_{1, c}}{\left(1-k_{c}\right) C_{1, c}}
$$

The $f_{1}$ values given by eqs. (1) and (2) must be equivalent. Thus, by equating eqs. (1) and (2) and solving for $\mathrm{C}_{\mathrm{l}, \mathrm{Nb}}$, a solidification path relation is obtained

$$
C_{1, N B}=C_{0, N B}\left[\frac{C_{0, C}-k_{C} C_{1, c}}{\left(1-k_{C}\right) C_{1, C}}{ }^{k_{N b}-1}\right.
$$

Eq. (3) describes the solidification path of the liquid during primary solidification of $\gamma$ assuming that $\mathrm{Nb}$ diffusion in the solid is negligible while $\mathrm{C}$ diffuses fast enough to maintain equilibrium. This relation is physically consistent at the limits of solidification. At the beginning of solidification, the liquid composition should equal the nominal composition for both solutes. Insertion of $C_{1, C}=C_{0 . C}$ into eq. (3) yields $C_{1 . N b}=C_{o . N b}$. Under equilibrium conditions for carbon, the liquid will reach a maximum concentration of $\mathrm{C}_{\mathrm{o}, \mathrm{C}} / \mathrm{k}_{\mathrm{C}}$ when solidification is complete while the $\mathrm{Nb}$ concentration in the liquid should tend toward infinity as predicted by the Scheil equation. Insertion of $C_{1}=C_{0 . C} / k_{C}$ into equation (3) yields $\mathrm{C}_{1, \mathrm{Nb}}=\infty$.

When the liquid composition intersects a line of two fold saturation on the liquidus surface, the remaining liquid $\left(f_{1}\right)$ will transform to the eutectic-type constituents (i.e., $\gamma / \mathrm{NbC}$ and $\gamma /$ Laves). Thus, the value of $f_{l}$ at that point represents the total amount of eutectic-type constituent which exists in the final solidification microstructure. In order to calculate the total volume fraction of eutectic-type 
constituent, the line of two fold saturation on the liquidus surface is first represented by a linear equation. For the two solutes of interest here:

$$
c_{1, C}=a+b c_{1, N b}
$$

Here, $\mathbf{a}$ is the $\mathrm{C}$ content at the line of two fold saturation between $\gamma$ and $\mathrm{NbC}$ at $0 \mathrm{wt} \% \mathrm{Nb}$ and $\mathbf{b}$ is the slope of the line. In order to find the intersection of the primary solidification path and the line of two fold saturation, eq. (4) is first solved in terms of $C_{I N \mathrm{Nb}}$

$$
c_{1, N b}=\frac{c_{1, c}-a}{b}
$$

and eqs. (3) and (5) are equated

$$
\frac{C_{1, C}-a}{b}=C_{0, N b}\left(\frac{C_{1, c}}{C_{0, C}}\right)^{\frac{k_{N b}-1}{k_{C}-2}}
$$

Eq. (6) provides a unique value of carbon content in the liquid, $\mathrm{C}_{1 . \mathrm{C}}$, in terms of the nominal alloy composition $\left(\mathrm{C}_{\mathrm{o} . \mathrm{Nb}}\right.$ and $\left.\mathrm{C}_{\mathrm{o} . \mathrm{C}}\right)$ and distribution coefficients $\left(\mathrm{k}_{\mathrm{Nb}}\right.$ and $\left.\mathrm{k}_{\mathrm{C}}\right)$ for the two solutes. This value of $\mathrm{C}_{\mathrm{l} . \mathrm{C}}$ defines the $\mathrm{C}$ content in the liquid where the solidification path intersects the line of two fold saturation. The corresponding $\mathrm{Nb}$ content in the liquid, $\mathrm{C}_{\mathrm{I}, \mathrm{Nb}}$, is given by substituting this value of $\mathrm{C}_{\mathrm{IIC}}$ into either eq. (3) or (5). Once this particular value of $C_{1, N b}$ is known, it is used in eq. (1) to calculate the remaining fraction of liquid which transforms to eutectic-type constituents.

Once the primary solidification path intersects the line of two fold saturation between $\gamma$ and $\mathrm{NbC}$, additional terms are needed in the mass balance equations to account for formation of two solid phases $(\gamma+\mathrm{NbC})$ from the liquid. This has been considered in detail [4] for the present set of conditions (i.e., negligible solid state diffusion of $\mathrm{Nb}$ and infinitely fast diffusion of carbon) and the final relation between fraction liquid $\left(f_{1}\right)$ and liquid composition $\left(C_{I, C}, C_{1, N b}\right)$ is given by

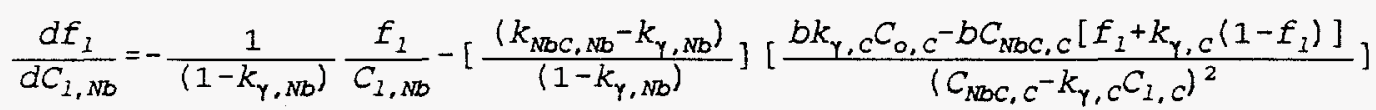

Where $k_{i j}$ is the distribution coefficient (given by the ratio of solid to liquid composition) for element $\mathbf{j}$ in the $\mathbf{i}$ phase. The distribution coefficients for $\mathrm{Nb}$ and $\mathrm{C}$ in $\gamma$ are assumed to be constant at the values shown in Table 2. The $\mathrm{NbC}$ phase is a stoichiometric compound so the composition of $\mathrm{NbC}, \mathrm{C}_{\mathrm{NbC.Nb}}$, and $\mathrm{C}_{\mathrm{NbC.C}}$ are constant at $90.5 \mathrm{wt} \% \mathrm{Nb}$ and $9.5 \mathrm{wt} \% \mathrm{C}$, respectively [4,9]. Thus, the distribution coefficients for $\mathrm{Nb}$ and $\mathrm{C}$ in the $\mathrm{NbC}$ phase can be calculated from knowledge of the liquid composition at any point during solidification.

Eq. (7) can be used to calculate solute redistribution during the eutectic-type $L \rightarrow(\gamma+\mathrm{NbC})$ reaction using a finite difference technique in the following manner: The first values of $f_{1}, C_{1 . N b}$, and $\mathrm{C}_{\mathrm{I} . \mathrm{C}}$ are calculated from the intersection of the solidification path and line of two fold saturation, as given by eqs. (3), (5), and (6). These values are used to calculate the first value of $\left(\mathrm{df}_{\mathrm{l}} / \mathrm{dC}_{\mathrm{IN \textrm {Nb }}}\right)_{1}$. The value of $\left(\mathrm{C}_{1 . N \mathrm{Nb}}\right)_{1}$ is incremented by a very small amount, $\Delta \mathrm{C}_{1 . \mathrm{Nb}}$, along the line of two fold saturation to a new value of $\left(\mathrm{C}_{1, N \mathrm{Nb}}\right)_{2}=\left(\mathrm{C}_{1, \mathrm{Nb}}\right)_{1}+\Delta \mathrm{C}_{\mathrm{IN \textrm {Nb }}}$. The corresponding value of $\left(\mathrm{C}_{\mathrm{l}, \mathrm{C}}\right)_{2}$ is determined through eq. (4). The corresponding value of $\left(\mathrm{f}_{\mathrm{l}}\right)_{2}$ is calculated by a small extrapolation of the value of $\left(\mathrm{df}_{\mathrm{l}} / \mathrm{dC}_{\mathrm{lN \textrm {Nb }}}\right)_{1}$ by 


$$
\left\langle f_{1}\right)_{2}=\left(f_{1}\right)_{1}+\left(\frac{d f_{1}}{d C_{1, N b}}\right)_{1} \Delta C_{1, N b}
$$

The values of $\left(\mathrm{C}_{1 . \mathrm{Nb}}\right)_{2},\left(\mathrm{C}_{1 . \mathrm{C}}\right)_{2}$, and $\left(\mathrm{f}_{1}\right)_{2}$ are then put back into eq. (7) and the calculations are repeated. The values of $\mathrm{k}_{\mathrm{NbC}, \mathrm{Nb}}$ and $\mathrm{k}_{\mathrm{NbC}, \mathrm{C}}$ are calculated at each step by knowledge of the $\mathrm{NbC}$ and liquid compositions. When the values of $C_{1 . N b}$ and $C_{1 . C}$ reach the class II reaction point where the $L \rightarrow(\gamma+$ $\mathrm{NbC})$ transformation is replaced by the $L \rightarrow(\gamma+$ Laves $)$ reaction, the remaining fraction liquid at that point transforms to the $\gamma /$ Laves eutectic-type constituent and solidification is complete. This procedure provides the relation between the fraction liquid and liquid composition at any point along the line of two fold saturation which, in turn, permits calculation of the volume fractions of each eutectic-type constituent present in the as solidified microstructure. More details of the calculation scheme are presented in [4].

\section{Modeling Results}

The parameters used to calculate the compositions and fractions of each phase forming during solidification are summarized in Table 3 . The values of $\mathrm{C}_{\mathrm{Nb}, L \rightarrow(\gamma+L \text { aves })}$ and $\mathrm{C}_{\mathrm{C} L \rightarrow(\gamma+L \text { aves })}$ listed in Table 3 represent the point of the class II reaction on the solidification. This point was determined through EPMA data [4]. When the $\mathrm{Nb}$ and $\mathrm{C}$ contents in the liquid reach this point, the remaining liquid $\left(\mathrm{f}_{1}\right)$ transforms to the $\gamma /$ Laves constituent $\left(f_{\gamma / \text { Laves }}\right.$ ) and the calculations are terminated. The constants a and b were determined by linear regression analysis from the point of $\left(\mathrm{C}_{\mathrm{Nb}, \mathrm{L} \rightarrow(\gamma+\mathrm{L} \text { aves })}, \mathrm{C}_{\mathrm{C} . \mathrm{L} \rightarrow(\gamma+\mathrm{Laves})}\right)$ to the data points on the line of two fold saturation.

Table 3. Summary of solidification parameters used in finite difference calculations.

\begin{tabular}{|c|c|c|c|}
\hline QUANTITY & Ni Base Alloys & Fe Base Alloys & UNITS \\
\hline$k_{\gamma \text { Nb }}$ & 0.46 & 0.25 & unitless \\
\hline $\mathrm{k}_{\gamma \mathrm{C}}$ & 0.27 & 0.27 & unitless \\
\hline $\mathrm{a}$ & 0.98 & 1.24 & $\mathrm{wt} \% \mathrm{C}$ \\
\hline $\mathrm{b}$ & -0.04 & -0.06 & $\mathrm{wt} \% \mathrm{C} / \mathrm{wt} \% \mathrm{Nb}$ \\
\hline $\mathrm{C}_{\mathrm{Nb.L} \rightarrow(\gamma+\text { Laves })}$ & 23.1 & 20.4 & $\mathrm{wt} \% \mathrm{Nb}$ \\
\hline $\mathrm{C}_{\mathrm{C}, \mathrm{L} \rightarrow(\gamma+\text { Laves })}$ & 0.03 & 0.03 & $\mathrm{wt} \% \mathrm{C}$ \\
\hline
\end{tabular}

Primary $\mathrm{L} \rightarrow \gamma$ Solidification The solidification path of each alloy was calculated via eq. (3) and plotted on the respective solidification surface. The results of the calculations are presented in Figure 6 . Figures $6 \mathrm{a}$ and $6 \mathrm{~b}$ plot typical results for the $\mathrm{Ni}$ base and $\mathrm{Fe}$ base alloys that have similar $\mathrm{Nb}$ levels, but variations in $\mathrm{C}$ content. (The nominal alloy composition is easily read by the start of the solidification path.) Figure $6 \mathrm{c}$ compares the solidification paths of $\mathrm{Ni}$ base alloys with similar $\mathrm{C}$ contents and variations in $\mathrm{Nb}$, and Figure $6 \mathrm{~d}$ compares the solidification paths of a $\mathrm{Ni}$ base and Fe base alloy with similar levels of solute elements ( $\mathrm{Nb}, \mathrm{Si}$, and $\mathrm{C}$ ). The alloy number of each path is denoted at the intersection point between the primary solidification path and line of two fold saturation. The solidification path for each alloy initiates at the nominal composition and generally progresses toward the line of two fold saturation between $\gamma$ and $\mathrm{NbC}$ as the liquid becomes enriched in $\mathrm{Nb}$ and $\mathrm{C}$. When the primary $L \rightarrow \gamma$ path strikes the line of two fold saturation, solidification then proceeds along the line of two fold saturation in the direction of decreasing temperature (i.e., toward the $\gamma$ - NbC "binary"). The amount of solid formed during primary solidification is proportional to the total distance of the primary solidification path. This relation is useful, as it allows for fast, qualitative interpretations of alloying effects by simple visual inspection of the results.

These diagrams provide several key points concerning the solidification behavior of these alloys. First, it is readily apparent that the point of intersection between the primary solidification path and line of two fold saturation is a strong function of $\mathrm{C}$ content. Although $\mathrm{C}$ additions are intuitively expected 

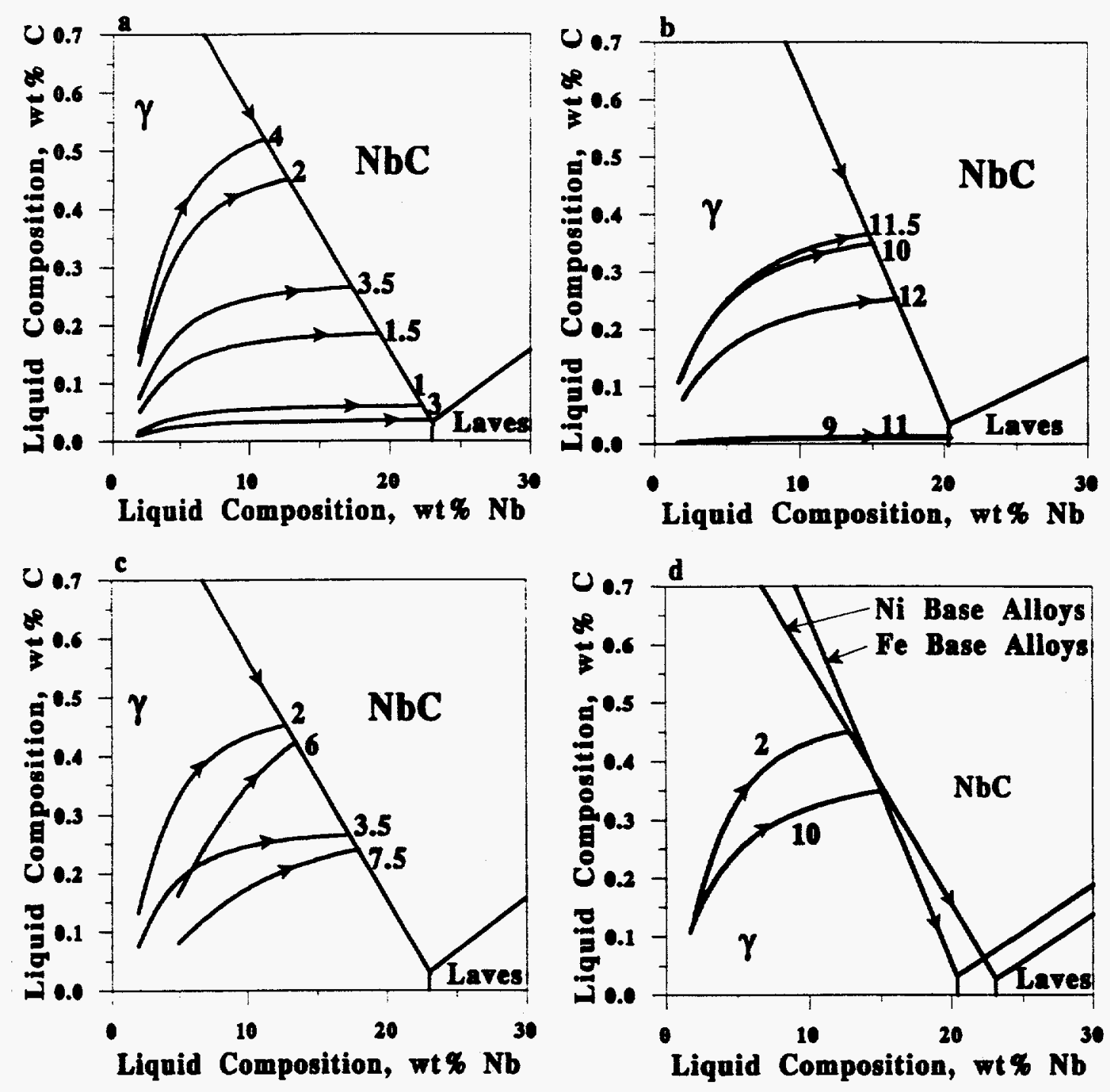

Figure 6. Calculated solidification paths.

to promote the $\gamma / \mathrm{NbC}$ eutectic type constituent, this analysis provides a quantitative rationale for the observed behavior. As the $\mathrm{C}$ content is increased, the intersection point occurs at higher $\mathrm{C}$ contents. As a result, the liquid composition must "travel" a long distance down the $\mathrm{L} \rightarrow(\gamma+\mathrm{NbC})$ line of two fold saturation, forming $\gamma / \mathrm{NbC}$ as it travels, before the $\gamma /$ Laves constituent can possibly form. At a given $\mathrm{C}$ content, the $\mathrm{Nb}$ concentration also has a significant effect on the primary solidification path. This is revealed by comparing Alloy 2 to 6 and Alloy 3.5 to 7.5 in Figure $6 \mathrm{c}$. When $\mathrm{Nb}$ is low, the $\mathrm{C}$ content in the liquid increases relatively quickly during the early stage of solidification. The rate of $\mathrm{C}$ build-up then decreases as the solute becomes depleted in the liquid. Since the length of the primary solidification paths for the high $\mathrm{Nb}$ alloys are shorter, these alloys will exhibit more liquid at the intersection point (i.e., more total eutectic-type constituent). The effect of matrix composition is presented in Figure $6 \mathrm{~d}$. Alloys 2 and 10 have very similar levels of solute content, but different matrix compositions. Thus, the main difference here is in the value of $\mathrm{k}_{\mathrm{Nb}}\left(\mathrm{k}_{\mathrm{Nb}}\right.$ in the Ni base Alloys $=0.46$ while $\mathrm{k}_{\mathrm{Nb}}$ in the $\mathrm{Fe}$ base Alloys $=0.25$ ). As $\mathrm{k}$ is reduced, $\mathrm{Nb}$ segregates more aggressively to the liquid. Thus, at any given level of $\mathrm{C}$ in the liquid, the $\mathrm{Fe}$ base alloys will always possess more $\mathrm{Nb}$. As a result, the $\mathrm{Fe}$ base alloys will have more liquid remaining after primary solidification, and the $\mathrm{Nb}$ content in that remaining liquid will be higher. These two effects from the reduced $\mathrm{k}_{\mathrm{Nb}}$ value are the primary reasons for the higher amount of total eutectic-type constituents observed in the Fe base alloys. The accuracy of this pseudo-ternary approach for the primary $L \rightarrow \gamma$ reaction portion of solidification can 
be evaluated by comparing the values of calculated and measured amounts of total eutectic-type constituent. The results are plotted in Figure 7, and there is good agreement between calculated and measured total eutectic-type constituent.

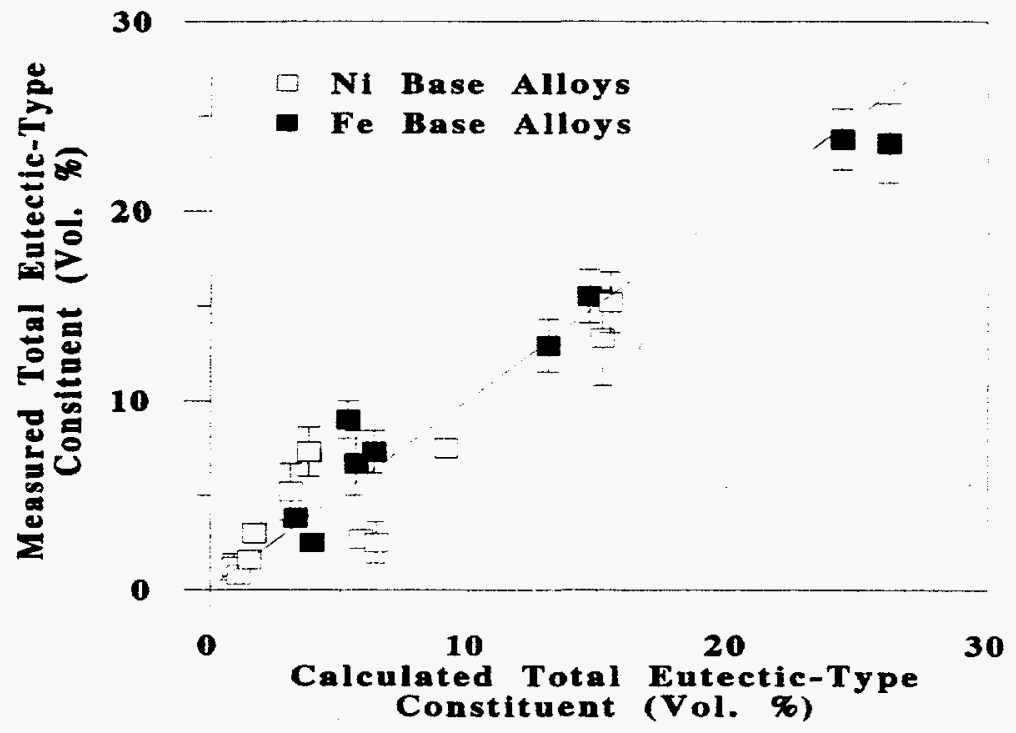

Figure 7. Comparison of calculated and measured amounts of total eutectic-type constituent.

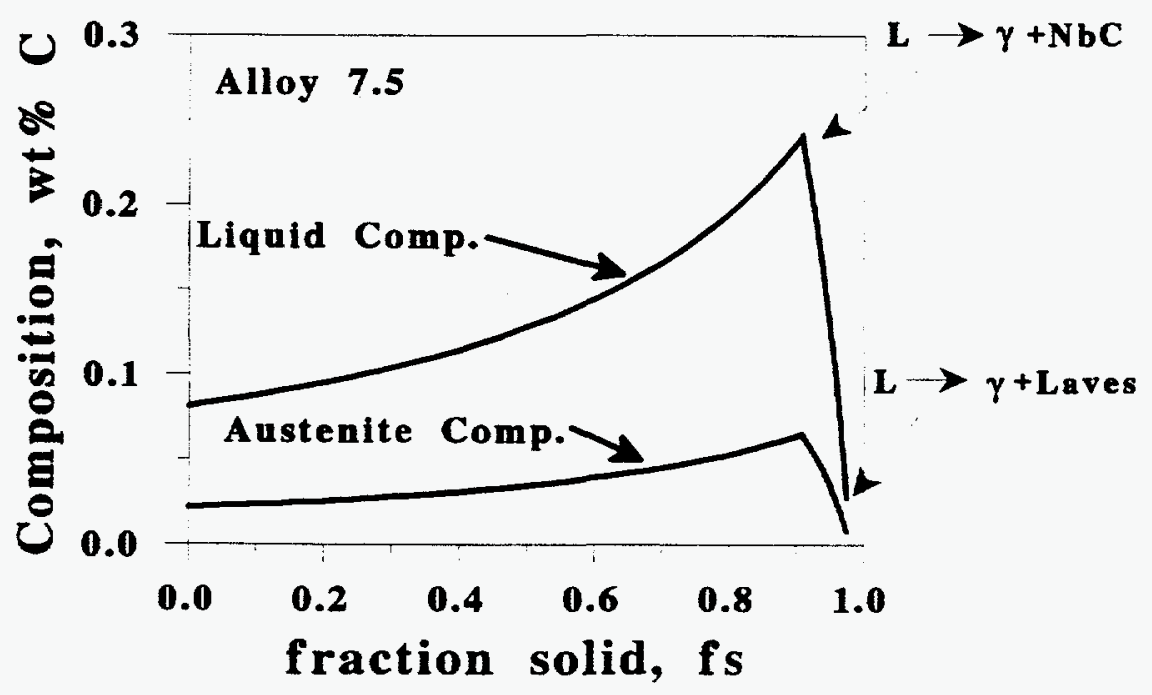

Figure 8. Calculated austenite and liquid carbon contents as a function of fraction solidified.

Eutectic-Type Solidification Figure 8 shows typical results (using Alloy 7.5 as an example) for the entire solidification process, where solute redistribution during primary solidification is calculated with eq. (3) and the eutectic-type $\mathrm{L} \rightarrow(\gamma+\mathrm{NbC})$ reaction is calculated with eq (7). The figure shows the variation in carbon content in the $\gamma$ and liquid phases during solidification. Primary $\mathrm{L} \rightarrow \gamma$ solidification occurs until there is 0.10 volume fraction liquid remaining with $0.24 \mathrm{wt} \% \mathrm{C}$, at which point the $\mathrm{L} \rightarrow$ $(\gamma+\mathrm{NbC})$ reaction is initiated. The $\mathrm{L} \rightarrow(\gamma+\mathrm{NbC})$ reaction depletes the liquid of carbon until there is 0.02 volume fraction remaining liquid at $0.03 \mathrm{wt} \% \mathrm{C}$, at which point the $\mathrm{L} \rightarrow(\gamma+$ Laves $)$ reaction is initiated. The calculations are terminated at this point, and the alloy is predicted to have 0.10 volume fraction of total eutectic ( 0.08 volume fraction $\gamma / \mathrm{NbC}$ plus 0.02 volume fraction $\gamma /$ Laves). The measured and calculated values of the individual eutectic-type constituents for all the alloys are compared in the Figure 9. The reasonable agreement between measured and calculated values confirms that the model developed here correctly captures the major factors controlling the solidification behavior of this important class of alloys. In addition, the model is general enough to apply to other alloy 
systems in which the diffusion behavior of one solute is high enough to maintain equilibrium during. solidification.
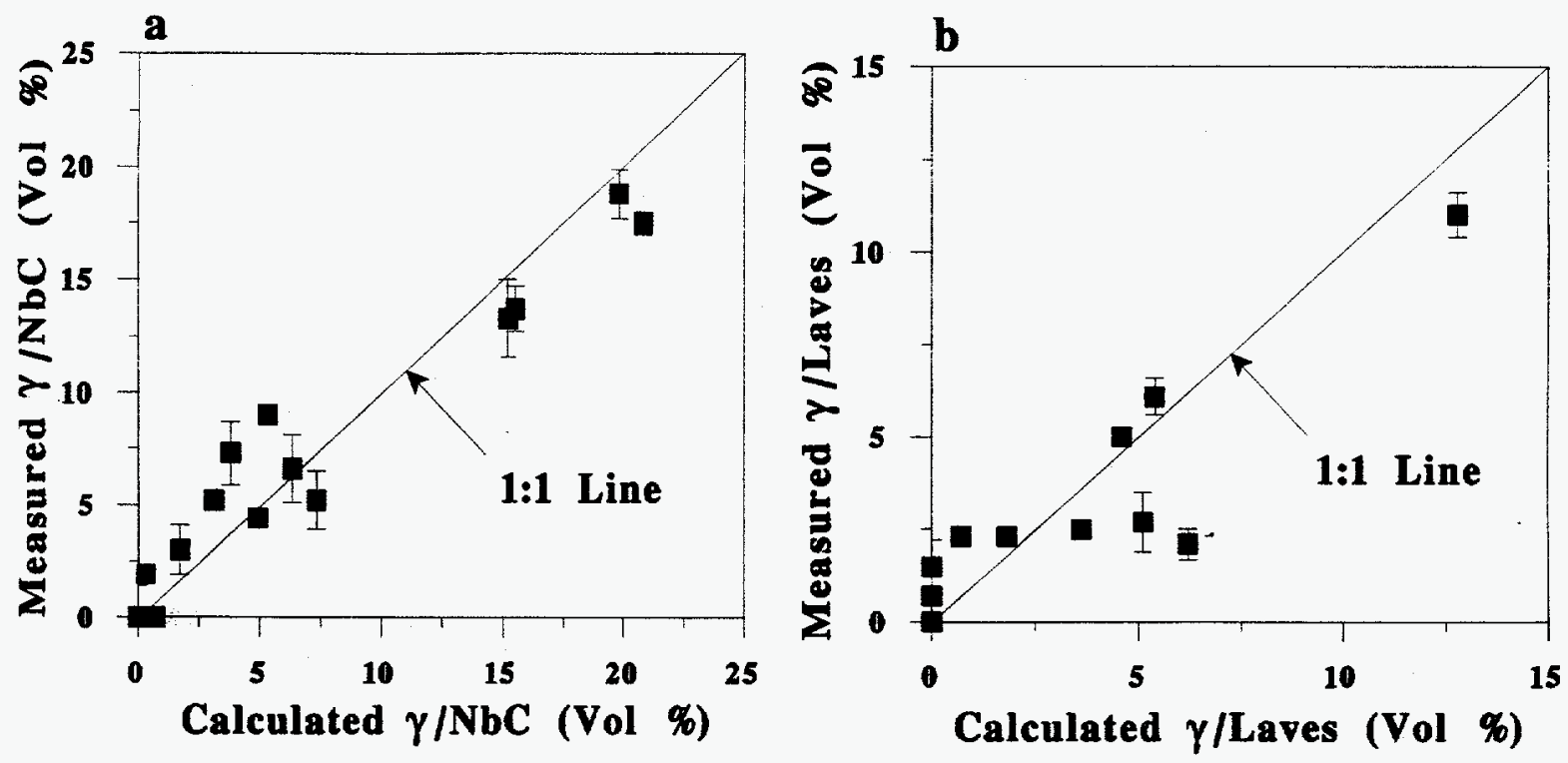

Figure 9. Comparison of measured and calculated values of the individual eutectic-type constituents .

\section{CONCLUSIONS}

Solute redistribution and microstructural evolution have been modelled for experimental alloys which simulate compositions of $\mathrm{Ni}$ base and $\mathrm{Fe}$ base superalloys containing $\mathrm{Nb}, \mathrm{Si}$, and $\mathrm{C}$. The multicomponent alloys were modelled as a ternary system by grouping the matrix (Fe,Ni,Cr) elements together as the "solvent" to form the $\gamma$ component of the $\gamma-\mathrm{Nb}-\mathrm{C}$ "ternary system". The variation in fraction liquid and liquid composition during the primary $\mathrm{L} \rightarrow \gamma$ and eutectic type $\mathrm{L} \rightarrow(\gamma+\mathrm{NbC})$ stages of solidification were calculated for conditions of negligible $\mathrm{Nb}$ diffusion and infinitely fast $\mathrm{C}$ diffusion in the solid phase. The model results permit quantitative interpretations of compositionmicrostructure relations in these $\mathrm{Nb}$ bearing experimental alloys and should provide useful insight into comparable commercial alloy systems as well.

\section{REFERENCES}

1. M.J. Cieslak, T.J. Headley, T. Kollie, and A.D. Romig, Jr., Metallurgical Transactions A, 1988, Vol. 19A, pp. 2319-2331.

2. Nakao, H. Ohshige, S. Koga, H. Nishihara, and J. Sugitani, Joumal of the Japan Welding Society, 1982, Vol. 51, pp. 989-995.

3. G.A. Knorovsky, M.J. Cieslak, T.J. Headley, A.D. Romig, Jr., and W.F. Hammetter, Metallurgical Transactions A, 1989, Vol. 20A, pp. 2149-2158.

4. J.N. DuPont, Ph.D. Dissertation, Lehigh University, Bethlehem, PA 18015, January, 1997.

5. H.H. Stadelmaier and M.L. Fiedler, Z. Metallkd., 1975, vol. 66 (4), pp. 224-225.

6. B. Radhakrishnan and R.G. Thompson, Metallurgical Transactions A, 1989, Vol.20A, pp. 2866-2868.

7. Z. Blazina and R. Trojko, J. Less Common Metals, 1986, vol. 119, pp. 297-305.

8. S.T. Wlodek, Trans. Am. Soc. Met., 1963, vol. 56, pp. 287-303.

9. M. Kajihara, T. Yoshikawa, M. Kikucki, and K. Yamauchi, Iron and Steel Institute of Japan, Vol. 32, No. 6, 1992, pp. 755-763.

10. F.N. Rhines, Phase Diagrams in Metallurgy, R.F. Mehl and M.B. Beaver (Eds.), McGraw Hill, New York, NY, 1956, pp. 175-185.

11. Metals Handbook, 8th ed., American Society for Metals, 1973, vol. 8.

12. Mehrabian and M.C. Flemings, Metallurgical Transactions A, 1970, Vol. 1, pp. 455-464.

13. Scheil: Z. Metallk., 1942, Vol. 34, p. 70.

14. T.W. Clyne and W. Kurz, Metallurgical Transactions A, 1981, Vol. 12A, pp. 965-971.

$\frac{\text { Acknowledment }}{\text { Sandia is a Multiprogram laboratory openated by Sandia Conponation, a Lockheed }}$ Sandia is a Multiprogram laboratory openated by Sandia Corponation, ander Contract DE-ACO4-94AL85000,
Martin Company, for the United States Departmont of Energy under Con 